\title{
Experimental and Numerical Analysis of a Simple Core Loss Calculation for AC Filter Inductor in PWM DC-AC Inverters
}

\author{
Kyoung-Jun Lee ${ }^{*}$, Honnyong Cha ${ }^{* *}$, Jong-Pil Lee ${ }^{* * *}$, Dong-Wook Yoo ${ }^{* * *}$, and Hee-Je Kim ${ }^{\dagger}$ \\ $\dagger^{\dagger}$ Dept. of Electrical Eng., Pusan National University, Busan, Korea \\ ${ }^{* *}$ School of Energy Engineering, Kyungpook National University, Daegu, Korea \\ ${ }^{* * *}$ Power Conversion \& Control Research Center, KERI, Changwon, Korea
}

\begin{abstract}
This paper introduces a simple core loss calculation method for output filter inductor in pulse width modulation (PWM) DC-AC inverter. Amorphous C-core (AMCC-320) is used to analyze the core loss. In order to measure core loss of the output filter inductor and validate the proposed method, a single-phase half-bridge inverter and a calorimeter are used. By changing switching frequency and modulation index (MI) of the inverter, core loss of the AMCC-320 is measured with the lab-made calorimeter and the results are compared with calculated core loss. The proposed method can be easily extended to other core loss calculation of various converters.
\end{abstract}

Key words: Amorphous c-core, Calorimeter, Core loss, Filter inductor, PWM DC-AC inverter, Steinmetz equation

\section{INTRODUCTION}

Magnetics such as inductors and transformers take significant portion in most power electronics converters in terms of volume, weight, and cost. A lot of research efforts, however, have been focused mainly on topology design and control method while very few researches have been conducted on magnetics.

In magnetics design, there are several issues to be considered for compact and cost-effective design. First, selection of the core material and winding geometry is important. Secondly, all the losses incurred inside magnetics should be able to be calculated for optimum design [1]-[3]. If we take inductor as an example, there are mainly two losses in inductor; core loss and winding loss. For DC-DC converters, core loss in the inductor can be easily calculated by using core loss equation provided by the manufacturer

Manuscript received Jun. 18, 2012; revised Oct. 21, 2012

Recommended for publication by Associate Editor Jin Hur.

${ }^{\dagger}$ Corresponding Author:heeje@pusan.ac.kr

Tel:+82-51-510-2770, Fax:+82-51-510-0212, Pusan National Univ.

*Dept. of Electrical Eng., Pusan National University, Korea

${ }_{* * *}^{* *}$ School of Energy Engineering, Kyungpook National University, Korea

${ }^{* * *}$ Power Conversion \& Control Research Center, KERI, Korea because flux swing in the magnetic core is relatively constant during operation. However, core loss calculation in the output filter inductor of PWM DC-AC inverter is not an easy task because the flux swing in this case is not constant in each switching interval. The varying flux swing is caused by the change of inverter output voltage.

Up to the present, many methods have been proposed to calculate core loss in AC filter inductor [4]-[11]. Most of the previous theoretical approaches to core loss are based on some form of the Steinmetz equation shown in (1), which expresses loss density as power law with fixed exponent of frequency $(f)$ and flux density $(B)$ [12]-[14], [27]-[29].

$$
P=k f^{\alpha} B^{\beta}
$$

In (1), $k, \alpha$ and $\beta$ are material parameters, where $f$ and $B$ represent the frequency and flux density of the core, respectively. $P$ is the power loss per unit volume and has the units of $\mathrm{W} / \mathrm{m}^{3}$.

In [15], [16] modified Steinmetz equation and behavioral model for inductor core materials are used to calculate the core loss in output filter inductor. In [17], [26], expanded core loss map which takes the inductor dc bias condition into account was proposed to evaluate inductor core loss.

Although the above mentioned approaches are useful and 
accurate, the process and method used in those works are quite complex and sometimes requires lots of back data to calculate the core loss. When calculating core loss of AC filter inductor in high power conversion system such as MW class wind power generation system, it is very difficult to acquire experimental database of core loss map. Therefore, practically engineers need the way of a bit less accurate but quick and easy to estimate the core loss of AC filter inductor in industrial applications.

In this paper, a very simple but effective way of calculating $\mathrm{AC}$ inductor core loss is proposed. In order to verify effectiveness of the proposed core loss calculation method, a calorimeter is built and the measured core losses are compared with the calculated ones.

\section{CALORIMETER TEST}

Traditionally, there are mainly two kinds of measurement: electrical measurement and calorimetric measurement. The electrical measurement uses the product of voltage and current which gives a power loss of the device under test (DUT). For this measurement, such equipments as a wattmeter, a digital oscilloscope and a power analyzer are required [18]-[23]. However, for high frequency applications, such as a PWM DC-AC inverter, electrical measurements are not suitable due to the limited bandwidth of the equipments and possible measurement error.

Unlike the electrical measurements having the difficulties mentioned above, calorimetric methods are based on direct loss measurements with fairly good accuracy [24], [25]. In this paper, therefore, calorimetric methods are chosen to verify the proposed core loss calculation method.

Fig. 1 shows a picture of the calorimeter built in this paper to measure inductor core loss. Calorimeter box was made of Styrofoam insulation sheets which separate the hot air inside the box from the ambient air outside of the chamber, closed on top to make sure that there is no air outflow. A small dc fan is installed inside the calorimeter for air stabilization. However, even the small dc fan also consumes power and hence contributes to temperature increase inside the calorimeter. Therefore, a power offset needs to be taken into account for accurate measurement for DUT. During the experiment, the calorimeter is covered with another bigger paper box for improved thermal insulation, as shown in Fig. 1. The excitation source is connected to the inductor from outside the box.

Before measuring inductor core loss, a thermal resistance data of the calorimeter must be extracted first. Instead of an inductor, a $20 \Omega / 400 \mathrm{~W}$ metal clad resistor was installed inside the calorimeter and an adjustable DC voltage source was directly applied to the resistor to generate thermal energy. For each power level from 5 to $50 \mathrm{~W}$, the temperature inside the calorimeter was measured every 5 minutes from zero to

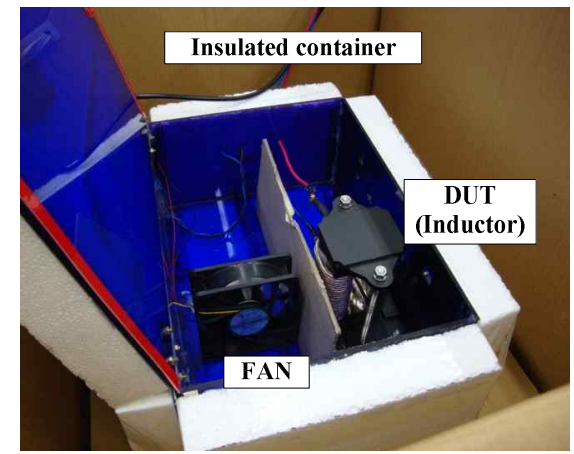

Fig. 1. Calorimeter for measuring core loss of output filter inductor.

TABLE I

Temperature $\left(\mathrm{T} ;{ }^{\circ} \mathrm{C}\right)$ AND CALORIMETER PARAMETER (A; $\left.{ }^{\circ} \mathrm{C} / \mathrm{MIN}\right)$

\begin{tabular}{c|c|c|c|c|c|c|c|c|c|c}
\hline Power(W) & 5 & 10 & 15 & 20 & 25 & 30 & 35 & 40 & 45 & 50 \\
\hline 0 & 20.9 & 21.0 & 19.3 & 16.8 & 19.8 & 18.9 & 20.2 & 19.3 & 20.2 & 22.1 \\
\hline 5 & 21.1 & 22.3 & 20.2 & 17.7 & 20.5 & 19.8 & 21.2 & 20.2 & 22.2 & 23.5 \\
\hline 10 & 21.2 & 23.0 & 21.1 & 19.0 & 21.7 & 21.4 & 23.0 & 22.1 & 24.5 & 25.7 \\
\hline 15 & 21.4 & 23.6 & 22.0 & 20.2 & 23.2 & 23.2 & 25.1 & 24.2 & 27.0 & 28.3 \\
\hline 20 & 21.7 & 24.2 & 22.9 & 21.5 & 24.7 & 24.8 & 27.1 & 26.5 & 29.5 & 31.0 \\
\hline 25 & 22.2 & 24.7 & 23.8 & 22.6 & 26.1 & 26.5 & 29.1 & 28.8 & 31.9 & 33.6 \\
\hline 30 & 22.9 & 25.2 & 24.8 & 23.7 & 27.4 & 28.4 & 31.1 & 31.0 & 34.4 & 36.3 \\
\hline 35 & 23.1 & 25.7 & 25.7 & 24.8 & 28.8 & 29.8 & 33.0 & 33.1 & 36.8 & 38.8 \\
\hline 40 & 23.1 & 26.1 & 26.4 & 26.0 & 30.2 & 31.3 & 34.8 & 35.2 & 39.2 & 41.3 \\
\hline$a\left(^{\circ} \mathrm{C} / \mathrm{min}\right)$ & 0.06 & 0.12 & 0.18 & 0.23 & 0.27 & 0.32 & 0.38 & 0.42 & 0.48 & 0.50 \\
\hline
\end{tabular}

40 minutes. After each experiment, the resistor is cooled down to the ambient temperature. Experimental results are shown in Table I. To linearize the temperature rise of calorimeter box, a slope $\left({ }^{\circ} \mathrm{C} / \mathrm{min}\right)$ in (2) for each power level is calculated by using the least square method of the linear regression calculations,

$$
T=a t+b
$$

where $\mathrm{T}$ is the temperature of the calorimeter box, $a$ is the slope $\left({ }^{\circ} \mathrm{C} / \mathrm{min}\right), t$ is the elapsed time ( $\left.\mathrm{min}\right)$ and $b$ is the offset temperature of the calorimeter box.

Parameters $a$ and $b$ are easily calculated through the least square fit function. For example, when the DUT inside of the calorimeter is excited at the power level of $50 \mathrm{~W}$, the temperature increases 0.5 degrees per minute (see Table I). Microsoft Excel was used to perform the linear regression calculation.

The acquired calorimeter data were also linearized to a trend line equation through the least square method, as follows

$$
y=0.0098 x+0.0026
$$

where $y$ is the slope $\left({ }^{\circ} \mathrm{C} / \mathrm{min}\right)$ and $x$ is the power. 


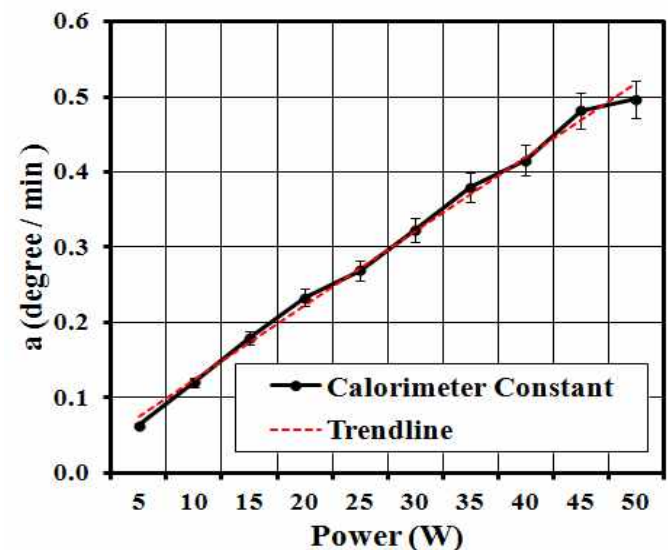

Fig. 2. Calorimeter parameter versus power.

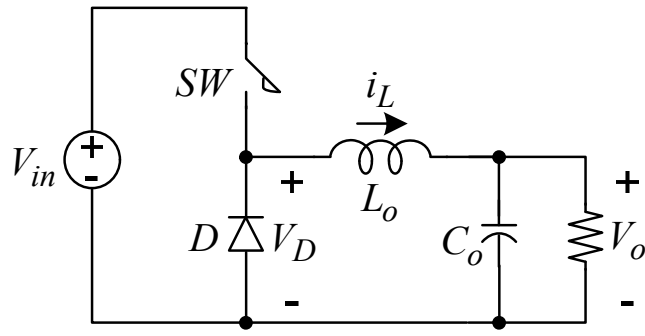

Fig. 3. Buck converter.

As shown in Fig. 2, the trend line shows linear relationship. Once the trend line equation is obtained, a temperature slope $\left({ }^{\circ} \mathrm{C} / \mathrm{min}\right)$ of any DUT in the calorimeter box can be matched to power (W), which is the core loss of inductor in this paper.

\section{INDUCTOR CORE LOSS CALCULATION IN PWM DC-DC CONVERTER}

Before we directly apply the proposed core loss calculation method to AC inductor, it is somewhat necessary to verify appropriateness of the proposed method. For this purpose, a simple $1 \mathrm{~kW}$ buck dc-dc converter as shown in Fig. 3 was built.

For the case of DC-DC converters such as the buck converter shown in Fig. 3, core loss in the inductor can be easily calculated by using the core loss equation provided by the manufacturer because flux swing $(\Delta B)$ in the magnetic core is relatively constant during steady-state operation. Table II shows the electrical specifications of the $1 \mathrm{~kW}$ buck converter and inductor designed.

To see the influence of DC bias condition on the lab-made inductor, the inductor was evaluated with the lab-made dc bias characters tester. This dc-bias characters tester employs Digital Signal Controller TMS320F2812 to control the DC bias current, measuring the maximum and minimum value of inductor current. For the case of inductor test such as the full bridge PWM converter shown in Fig. 4 (a), the DC current biased inductance can be easily calculated by using the following relations.
TABLE II

ELECTRICAL SPECIFICATIONS OF THE BUCK CONVERTER AND THE INDUCTOR

\begin{tabular}{|c|c|c|}
\hline \multirow{3}{*}{$\begin{array}{c}\text { Buck } \\
\text { converter }\end{array}$} & $\mathrm{V}_{\text {in }}$ & $250 \mathrm{~V}$ \\
\hline & Duty cycle (D) & 0.5 \\
\hline & $\begin{array}{l}\text { Switching frequency } \\
\qquad\left(f_{s w}\right) \text { variation }\end{array}$ & $\begin{array}{l}5 \mathrm{kHz}, 10 \mathrm{kHz}, \\
15 \mathrm{kHz}, 20 \mathrm{kHz}\end{array}$ \\
\hline \multirow{7}{*}{ Inductor } & Core material & Amorphous C-core (Metglas) \\
\hline & Core shape & U-shaped, AMCC-320 \\
\hline & $\begin{array}{l}\text { Maximum flux density } \\
\qquad\left(\mathrm{B}_{\max }\right)\end{array}$ & $1.65 \mathrm{~T}$ \\
\hline & $\begin{array}{l}\text { Effective magnetic path } \\
\text { length }\left(l_{\mathrm{e}}\right) \text { of the core }\end{array}$ & $32.5 \mathrm{~cm}$ \\
\hline & $\begin{array}{c}\text { Effective core } \\
\text { cross-sectional area }\left(\mathrm{A}_{\mathrm{e}}\right)\end{array}$ & $9 \mathrm{~cm}^{2}$ \\
\hline & Number of turns $(\mathrm{N})$ & $22 \mathrm{~T}$ \\
\hline & $\begin{array}{l}\text { Measured inductance } \\
\text { (L) at rated condition }\end{array}$ & $1.56 \mathrm{mH}$ \\
\hline
\end{tabular}

$$
L_{D U T}=V_{\text {in }} \frac{T_{S W}}{\Delta i_{L}}
$$

where $\Delta i_{L}$ is the current ripple of DC bias current and $T_{s w}=1 / f_{s w}$.

According to DC bias test results as shown in Fig. 4 (b), inductance value was reduced by only $3 \%$ of initial value at the rated current of $13 \mathrm{~A}$, confirming that the influence of a DC bias on lab-made inductor is small.

In order to calculate the inductor core loss, flux ripple (or flux swing, $\Delta B$ ) of the magnetic core should be first calculated by using the following equation.

$$
\Delta B=\frac{\left(V_{i n}-V_{o}\right) D T_{s w}}{N A_{e}}=\frac{V_{i n} T_{s w}}{L}(1-D) D
$$

where $D$ is the converter duty cycle and $T_{s w}=1 / f_{S w}$.

The inductor core loss now can be calculated by inserting flux ripple in (5) to the Steinmetz equation provided by the core manufacturer as follows

$$
P_{\text {core }}=(w t) \times k \times\left(f_{s w} / 1000\right)^{\alpha} \times B^{\beta}[W]
$$

,where $w t=2.167 \mathrm{~kg}, k=6.5, \alpha=1.51$ and $\beta=1.74$ for Metglas AMCC-320. In (6), $f$ is in $\mathrm{kHz}$ and $B$ is in Tesla.

In (6), $B$ should be replaced with $\Delta B / 2$ and multiplied by the form factor to consider rectangular inductor voltage waveform because Eq. (6) is generated by applying an ac sinusoidal voltage waveform to inductor. Form Factor is the ratio between the average value and the root mean square value of a sinusoidal waveform, which equal to 1.11 . Therefore, $B=1.11 \times \Delta B / 2$.

To measure the inductor core loss with the calorimeter 


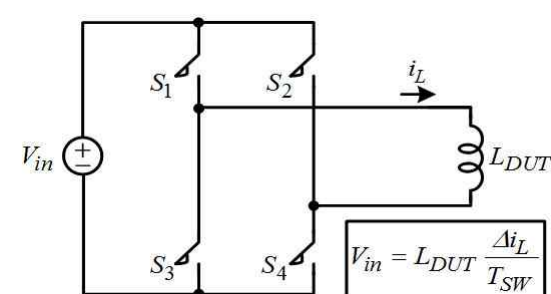

(a)

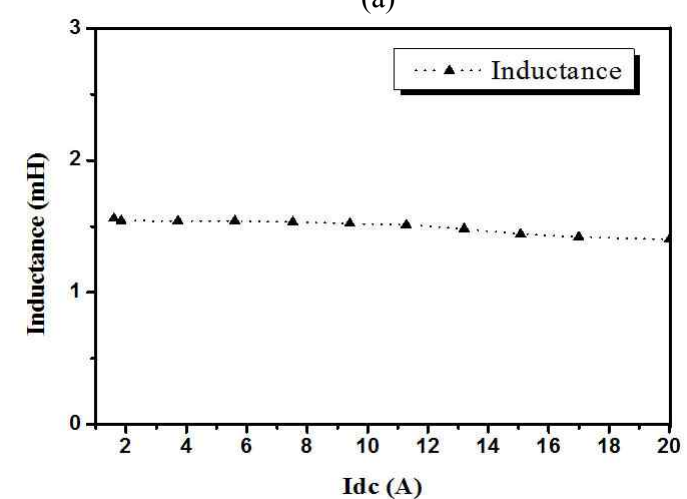

(b)

Fig. 4. Evaluation of dc bias characters of inductor.

TABLE III

COMPARISON OF CALCULATED AND MEASURED INDUCTOR CORE LOSS OF THE BUCK CONVERTER

\begin{tabular}{|c|c|c|c|c|}
\hline$f_{s w}$ & $5 \mathrm{kHz}$ & $10 \mathrm{kHz}$ & $15 \mathrm{kHz}$ & $20 \mathrm{kHz}$ \\
\hline$\Delta B$ & $0.631 \mathrm{~T}$ & $0.316 \mathrm{~T}$ & $0.21 \mathrm{~T}$ & $0.158 \mathrm{~T}$ \\
\hline Pc.calculated & $25.8 \mathrm{~W}$ & $22.0 \mathrm{~W}$ & $20.0 \mathrm{~W}$ & $18.8 \mathrm{~W}$ \\
\hline Pc.measured & $24.2 \mathrm{~W}$ & $20.1 \mathrm{~W}$ & $18.1 \mathrm{~W}$ & $16.1 \mathrm{~W}$ \\
\hline Error & $6.5 \%$ & $9.2 \%$ & $10.7 \%$ & $16.8 \%$ \\
\hline
\end{tabular}

designed in section II, the metal clad resistor was replaced with the $1 \mathrm{~kW}$ inductor for DUT, as shown in Fig. 3. To obtain as much information as possible on the core loss, the buck converter switching frequency was varied from $5 \mathrm{kHz}$ to $20 \mathrm{kHz}$. For each switching frequency, the buck converter was operated for 45 minutes. The temperature in the calorimeter was measured every 5 minutes and the corresponding slope was calculated by the same least square method mentioned in section II. After every experiment, the calorimeter was cooled down to ambient temperature and the next experiment was conducted for fair measurement.

Fig. 5 and 6 show experimental waveforms of the buck converter operating at $5 \mathrm{kHz}$ and $10 \mathrm{kHz}$, respectively, with all other parameters unchanged. As shown in Fig. 5 and 6, inductor current ripple is reduced as switching frequency increases. Table III compares the inductor core loss obtained. In this paper, the current density of inductor winding is intentionally made very small to minimize the effect of winding loss in the measurement and the calculated winding loss was almost $1 \mathrm{~W}$. Thus, the effect of winding loss is negligible and is not included in the calculation.

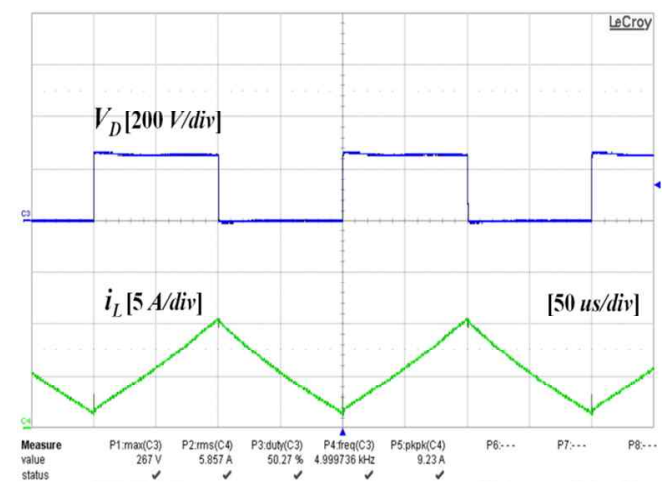

Fig. 5. Experimental waveforms of the buck converter when $f_{s w}=5 \mathrm{kHz}, D=0.5$.

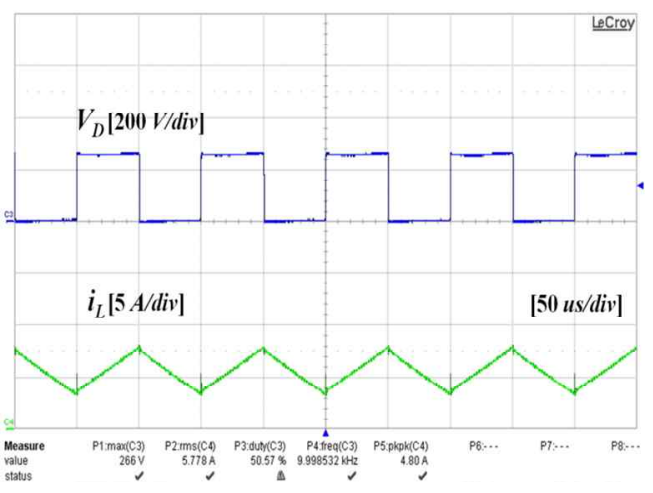

Fig. 6. Experimental waveforms of the buck converter when $f_{s w}=10 \mathrm{kHz}, D=0.5$.

Fig. 7 shows the plot of the inductor core losses measured using the calorimeter developed in this work at different switching frequencies and they are compared with the calculated core losses to find the discrepancy of the both method. With the increase of the switching frequency, $\Delta B$ decreases and inductor core loss decreases in both experiment and calculation. This can also be expected from (6) because the coefficient $\beta$ is greater than $\alpha$. Although there is some error between the measured and calculated results, they are in quite good agreement, as shown in Fig. 7. It is confirmed that the lab-made calorimeter can be applied to the measurement of $\mathrm{AC}$ filter inductor to prove the effectiveness of the proposed method.

\section{INDUCTOR CORE LOSS CALCULATION IN PWM DC-AC INVERTER}

In this Fig. 8 shows a $1 \mathrm{~kW}$ single-phase half-bridge (HB) PWM DC-AC inverter with LC output filter, where $V_{i n}=400$ $\mathrm{V}, L_{o}=1.65 \mathrm{mH}$ and $C_{o}=44 \mu \mathrm{F}$. The switching frequency of inverter is set to $4.8 \mathrm{kHz}, 9.6 \mathrm{kHz}$, and $19.2 \mathrm{kHz}$. The MI of inverter is varied to $0.5,0.8$ and 1.0 . 


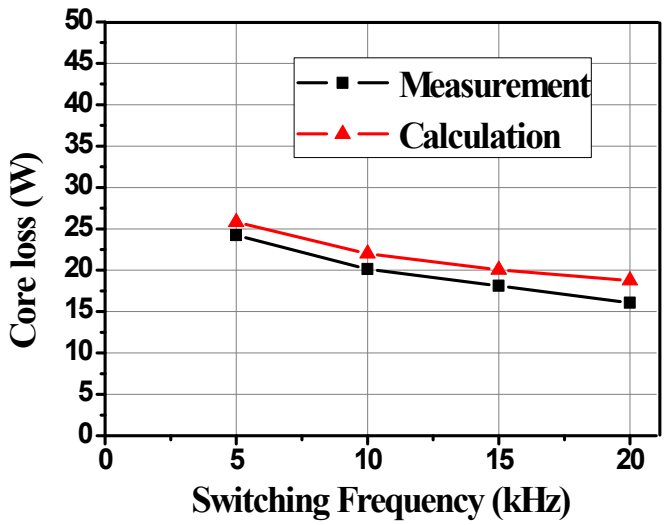

Fig. 7. Calculated and measured inductor core loss.

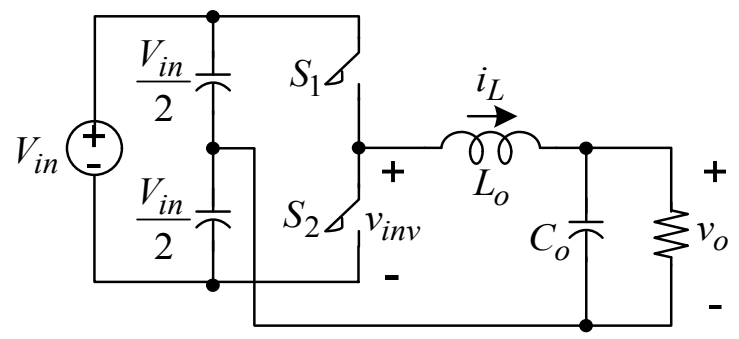

Fig. 8. Single-phase half-bridge inverter.

Similar to the inductor in buck dc-dc converter, the output filter inductor was also designed to minimize the winding loss and to generate enough core loss. A sinusoidal PWM (SPWM) method is used to generate $60 \mathrm{~Hz}$ output voltage waveform. For each switching frequency and MI of inverter, the AC filter inductor was excited for 45 minutes. The temperature in the calorimeter was measured by the same manner as in Section III.

Fig. 9 shows conceptual idea of the proposed method used to calculate AC output filter inductor core loss. As shown in Fig. 9, a $60 \mathrm{~Hz}$ fundamental frequency $\left(f_{o}\right)$ output voltage $\left(v_{o}\right)$ is first chopped down with high switching frequency $\left(f_{s w}\right)$. Therefore, there are $f_{s w} / f_{o}$ (defined as $n$ in this paper) number of pulses during one fundamental cycle. While the dc-dc converters producing a constant output voltage and hence results in a constant inductor current ripple (or constant flux ripple, $\Delta B$ ) over the entire operating period, the inductor current ripple of PWM DC-AC inverter during one fundamental cycle varies according to the switching PWM signals because $v_{o}$ is not constant during one fundamental cycle. Therefore, the flux ripple $(\Delta B)$ in inductor core also varies, which makes the core loss calculation in $\mathrm{AC}$ filter inductor complicated and challenging. The changing $\Delta B$ is represented as follows

$$
\Delta B\left(\theta_{j}\right)=\frac{V_{i n} T_{s w}}{N A_{e}}\left[1-D\left(\theta_{j}\right)\right] D\left(\theta_{j}\right)
$$

where $\Delta B\left(\theta_{j}\right)$ is the flux swing in each switching interval ( $\left.T_{s w}\right), j=1,2,3, \ldots ., n, N$ is the number of turns, and $A_{e}$ is the core cross-sectional area. By defining $m_{a}$ as inverter modulation index (MI), the inverter duty cycle $D\left(\theta_{j}\right)$ in each switching period is represented as follows

$$
D\left(\theta_{j}\right)=\frac{1+m_{a} \sin \left(\theta_{j}\right)}{2}
$$

Therefore, Eq. (7) can be rewritten as

$$
\Delta B\left(\theta_{j}\right)=\frac{V_{i n} T_{s w}}{4 N A_{e}}\left[1-m_{a}^{2} \sin ^{2}\left(\theta_{j}\right)\right]
$$

From core loss equation of the AMCC-320 given by the manufacturer, the inductor core losses in each switching interval are calculated as follows

$P_{c j}=\frac{(w t) \times k \times\left(f_{s w} / 1000\right)^{\alpha} \times\left(1.11 \times \Delta B\left(\theta_{j}\right) / 2\right)^{\beta}}{f_{s w}}$

,where $w t=2.167 \mathrm{~kg}, k=6.5, \alpha=1.51, \beta=1.74$.

In the proposed method shown in this paper, the B-H curve of each interval is assumed to be the closed loop, which is the premise for using Steinmetz equation supplied by the manufacturer. In (10), Steinmetz equation is divided by $f_{s w}$ because we only consider the core loss in each switching interval. The next step is to add all the core losses in one quadrant ( $\pi / 2 \sim \pi$, for example) and then multiply them by 4 to make one period. This is the core loss in one fundamental period, which is equal to $1 / 60 \mathrm{~s}$. Finally, this value is multiplied by $f_{o}$ as (11) because the total core loss per second is the summation over the 60 cycles.

$$
P_{\text {c.total }}=\underbrace{\left(\sum_{j=1}^{n / 4} P_{c j}\right) \times 4}_{\text {one period }} \times f_{o}
$$

Fig. 10 shows the plot of $\Delta B\left(\theta_{j}\right)$ when inverter MI is 1.0, 0.8 and 0.5. During one fundamental cycle, maximum value of flux swing ( $\Delta B_{\max }$ ) is the same regardless of the MI. However, minimum value of flux swing is different according to MI of inverter, which can also be expected from (9). While the flux swing reaches zero at $\mathrm{MI}=1.0$, the flux swing does not reach zero at $\mathrm{MI}=0.8$ and 0.5 . We can expect that the total flux swing during one fundamental cycle increases with the decrease of MI of inverter, with all other parameters unchanged. In this section, based on the proposed 


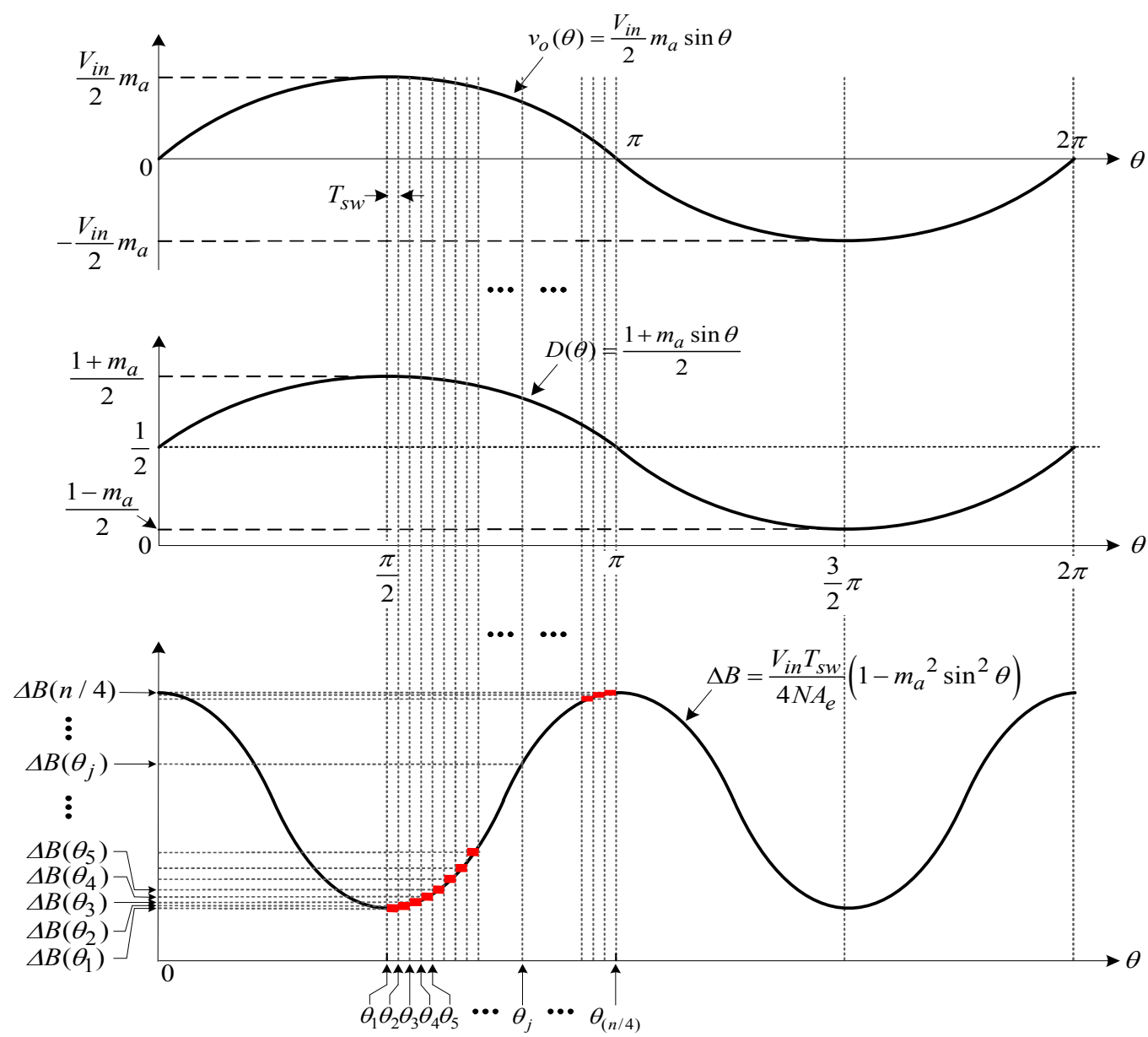

Fig. 9. Conceptual idea of the proposed core loss calculation method.

method, the AC filter inductor in a closed calorimeter is excited by changing the switching frequency and MI of inverter. Calculated and experimental results of the core loss for an $\mathrm{AC}$ filter inductor under various $\mathrm{MI}$ and switching frequency of the PWM inverter are presented and discussed.

Fig. 11 and Fig. 12 show the experimental waveform when the switching frequency is fixed to $4.8 \mathrm{kHz}$ and the MI is set to 0.5 and 0.8 , respectively. Fig. 13 shows the waveform when the switching frequency is $9.6 \mathrm{kHz}$ and the MI is 0.8. The inductor current ripple in Fig. 11 is larger than the one in Fig. 12, which is mainly due to the MI of inverter. Also, comparing the results of Fig. 12 and Fig. 13, inductor current ripple decreases with the increase of switching frequency when the MI is same. Fig. 14 shows the expanded waveforms of Fig. 12 around a zero crossing point of inductor current when the switching frequency is $4.8 \mathrm{~Hz}$ and the MI is 0.8. It is confirmed that the current ripple of inductor current is changed according to the duty cycle of SPWM.

As shown in Fig 15, the first step is to take the calorimeter box equation in Section II. In the second step, for each inverter experiment, the slope $\left({ }^{\circ} \mathrm{C} / \mathrm{min}\right)$ of the calorimeter is obtained. In the third step, this value is put into the $\mathrm{y}$ $\left({ }^{\circ} \mathrm{C} / \mathrm{min}\right)$ of (3). Finally, the $\mathrm{x}(\mathrm{W})$ is calculated, which is the core loss of each experiment.

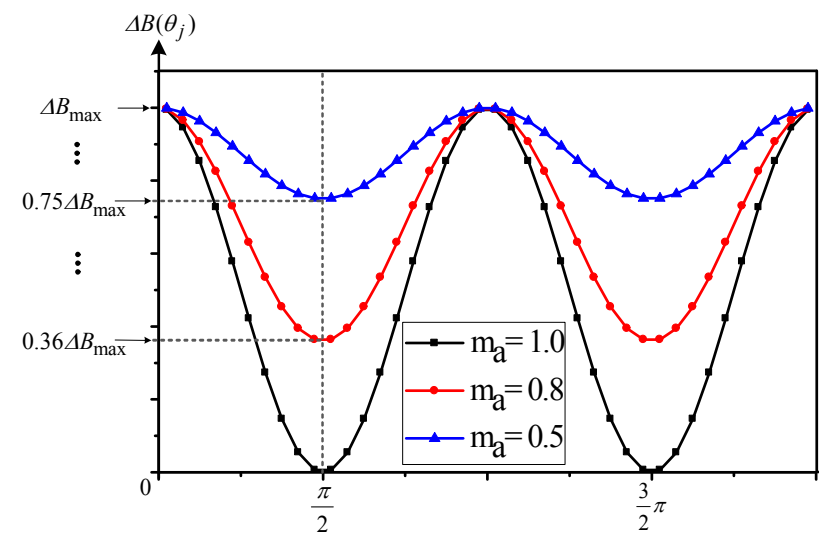

Fig. 10. Variation of $\Delta B$ as a function of modulation index $\left(m_{a}\right)$. 


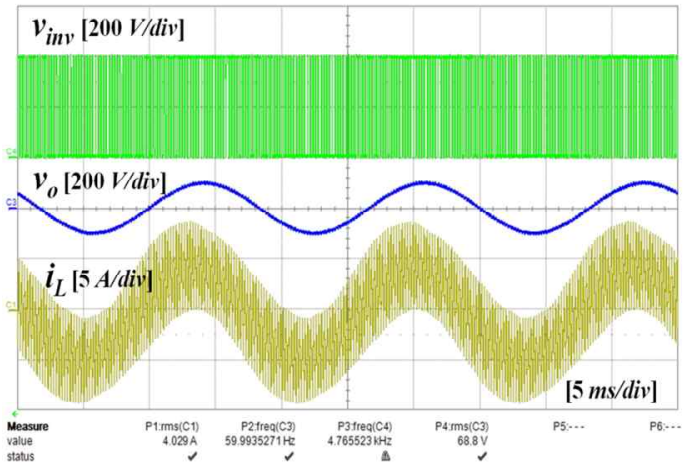

Fig. 11. Experimental waveforms when $f_{s w}=4.8 \mathrm{kHz}, m_{a}=0.5$.

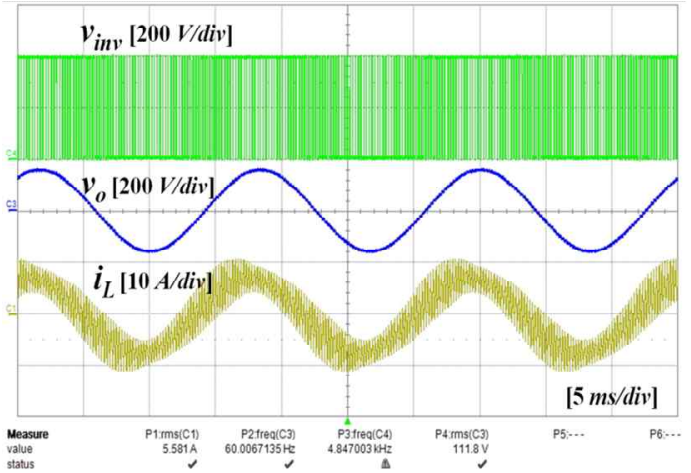

Fig. 12. Experimental waveforms when $f_{s w}=4.8 \mathrm{kHz}, m_{a}=0.8$.

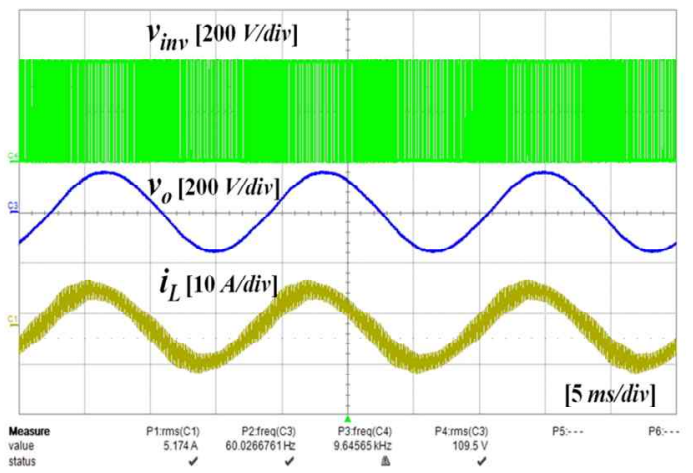

Fig. 13. Experimental waveforms when $f_{s w}=9.6 \mathrm{kHz}, m_{a}=0.8$.

Fig. 16 shows the inductor core losses measured using calorimeter at different $m_{a}$ and they are compared with the calculated ones. As shown in Fig. 16, the measured and calculated results are in fairly good agreement. The difference between measurement and calculation are mainly caused by the inductor winding loss (almost $1 \mathrm{~W}$ ) included in the calorimeter measurement and a very small portion of the unclosed loop B-H loop area [17]. We can see that the core loss of AC filter inductor decreases with the increase of the switching frequency and MI in accordance with theoretical considerations, when leaving all other parameters unchanged.

The proposed simple and practical technique is capable of

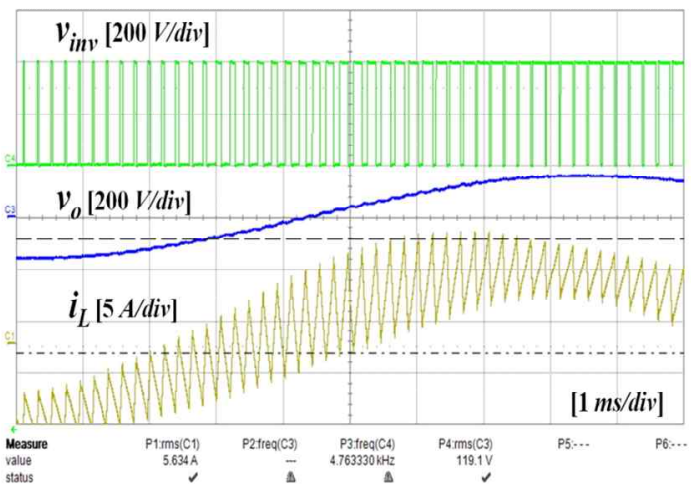

Fig. 14. Expanded waveforms of Fig. 11.

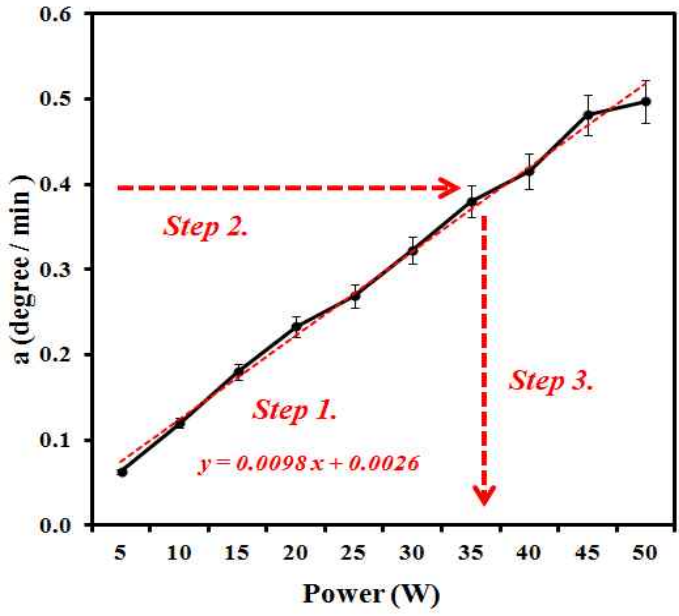

Fig. 15. Core loss calculation method.

TABLE IV

COMPARISON OF CALCULATED AND MEASURED INDUCTOR CORE LOSS

\begin{tabular}{|c|c|c|c|c|}
\hline \multirow{2}{*}{$m_{a}=1.0$} & $f_{S w}$ & $4.8 \mathrm{kHz}$ & $9.6 \mathrm{kHz}$ & $19.2 \mathrm{kHz}$ \\
\cline { 2 - 5 } & Pc.calculated & $23.1 \mathrm{~W}$ & $19.7 \mathrm{~W}$ & $16.8 \mathrm{~W}$ \\
\hline \multirow{2}{*}{$m_{a}=0.8$} & Pc.measured & $26.3 \mathrm{~W}$ & $23.0 \mathrm{~W}$ & $21.7 \mathrm{~W}$ \\
\hline \multirow{2}{*}{$m_{a}=0.5$} & Pc.calculated & $31.7 \mathrm{~W}$ & $27.1 \mathrm{~W}$ & $23.1 \mathrm{~W}$ \\
\cline { 2 - 5 } & Pc.measured & $35.9 \mathrm{~W}$ & $31.8 \mathrm{~W}$ & $27.8 \mathrm{~W}$ \\
\cline { 2 - 5 } & Pc.calculated & $46.2 \mathrm{~W}$ & $39.4 \mathrm{~W}$ & $33.7 \mathrm{~W}$ \\
\hline
\end{tabular}

predicting core losses for AC filter inductor in PWM DC-AC Inverters, employing only core loss equation specified by the manufacturer. An improvement of the lab-made calorimeter will be implemented to prove the effectiveness at higher power level tests, so that proposed methods can approach the actual core loss calculation of AC filter inductor in high power conversion system without the necessity of a massive experimental database.

Table IV compares the result of core loss calculation and measurement. 


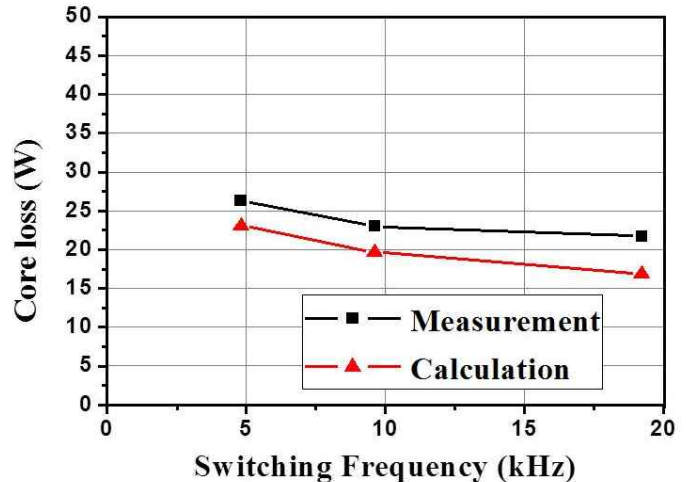

(a) $m_{a}=1.0$.

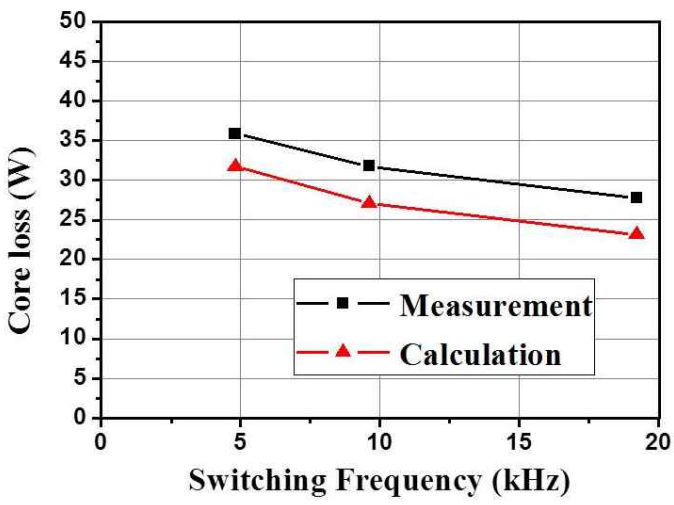

(b) $m_{a}=0.8$.

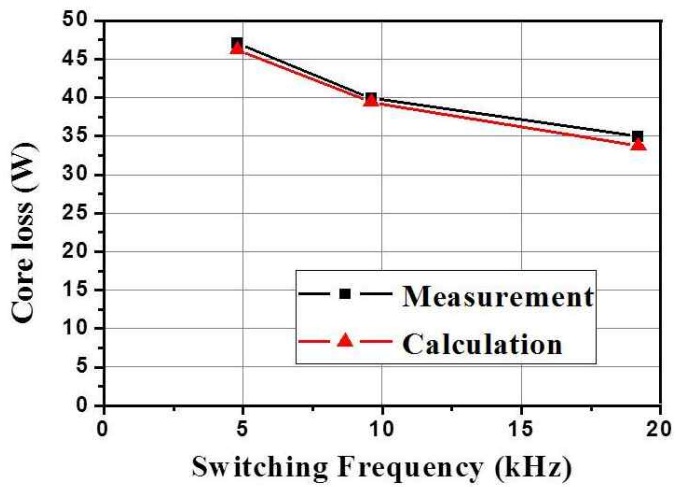

(c) $m_{a}=0.5$.

Fig. 16. Core loss of inverter output filter inductor according to the switching frequency and modulation index.

\section{CONCLUSIONS}

In this paper, a very simple but effective way of calculating core loss of the AC output filter inductor of PWM DC-AC inverter was presented. The proposed calculation method was verified with the thermal measurement in the lab-made calorimeter. The results confirm that the proposed method is very practical not only for calculation of the core loss, but also for designing AC filter inductor. By using the proposed method, one can expedite inductor design process quite successfully. The proposed method in different core materials should be equally applicable in further experiment.

\section{ACKNOWLEDGMENT}

This research was partly supported by the MKE (The Ministry of Knowledge Economy), Korea, under the CITRC (Convergence Information Technology Research Center) support program (NIPA-2012-H0401-12-1006) supervised by the NIPA (National IT Industry Promotion Agency.)

\section{REFERENCES}

[1] R. Boll, Soft Magnetic Materials, in The Vacuumschmelze Handbook, Heyden \& Son Ltd., London, pp. 13-108, 1979.

[2] N. Z. Yahaya, M. B. K. Raethar, and M. Awan, "Review on magnetic components," Journal of Power Electronics, Vol. 9, No. 2, pp. 180-187, Mar. 2009.

[3] A. Hren, M. Milanovic, and F. Mihalic, "Teaching magnetic component design in power electronics course using project based learning approach," Journal of Power Electronics, Vol. 12, No. 1, pp. 201-207, Jan. 2012.

[4] A. J. Moses and N. Tutkun, "Investigation of power loss in wound toroidal cores under PWM excitation," IEEE Trans. Magn., Vol. 33, No. 5, pp. 3763-3765, Sep. 1997.

[5] A. Boglietti, P. Ferraris, M. Lazzari, and M. Pastorelli, "About the possibility of defining a standard method for iron loss measurement in soft magnetic materials with inverter supply," IEEE Trans. Ind. Appl., Vol. 33, No. 5, pp. 1283-1288, Sep./Oct. 1997.

[6] A. I. Maswood and Z. K. Yoong, "Design aspects of a switch-mode transformer under wide input voltage variation," IEEE Trans. Ind. Electron., Vol. 53, No. 3, pp. 752-758, Jun. 2006.

[7] M. Amar and R. Kaczmarek, "A general formula for prediction of iron losses under non sinusoidal voltage waveform," IEEE Trans. Magn., Vol. 31, No. 5, pp. 2504-2509, Sep. 1995.

[8] A. Van den Bossche, V. C. Valchev, and G. B. Georgiev, "Measurement and loss model of ferrites with non-sinusoidal waveforms," in Conf. Rec.IEEE PESC, pp. 4814-4818, 2004.

[9] S.-H. Ko, S.-W. Lee, S.-R. Lee, C. V. Nayar, and C.-Y. Won, "Design considerations for a distributed generation system using a voltage-controlled voltage source inverter," Journal of Power Electronics, Vol. 9, No. 4, pp. 643-653, Jul. 2009.

[10] H. Kim, "Filter design for grid-connected single-phase inverters," Journal of Power Electronics, Vol. 9, No. 4, pp. 623-630, Jul. 2009.

[11] H. Kim and S.-K. Sul, "A novel filter design for output lc filters of pwm inverters," Journal of Power Electronics, Vol 11, No. 1, pp. 74-81, Jan. 2011.

[12] J. Li, T. Abdullah, and C. Sullivan, "Improved calculation of core loss with nonsinusoidal waveforms," in Proc. IEEE IAS 36th Annu. Meeting, pp. 2203-2210, 2001.

[13] J. Reinert, A. Brockmeyer, and R. W. De Doncker, "Calculations of losses in ferro- and ferromagnetic materials based on modified Steinmetz equation," in Proc. 34th Annu. IEEE Ind. Appl. Soc. Meeting, Vol. 3, pp. 2087-2092, 1999.

[14] W. A. Roshen, "A practical, accurate and very general core loss model for nonsinusoidal waveforms," IEEE Trans. Power Electron., Vol. 22, No. 1, pp. 30-40, Jan. 2007.

[15] J. Liu, T. G.Wilson, R. C.Wong, R.Wunderlich, and F. C. Lee, "A method for inductor core loss estimation in power factor correction applications," in Conf. Rec. IEEE APEC, pp. 439-445, 2002. 
[16] M. Albach, T. Durbaum, and A. Brockmeyer, "Calculating core losses in transformers for arbitrary magnetizing currents-A comparison of different approaches," in Conf. Rec. IEEE PESC, Vol. 2, pp. 23-27, 1996.

[17] T. Shimizu and S. Iyasu "A Practical Iron Loss Calculation for AC Filter Inductor Used in PWM Inverters," IEEE Trans. Ind. Electron., Vol. 56, No. 7, pp 2600-2609, Jul. 2009.

[18] S. Mukherjee, R. G. Hoft, and J. A. McCormick, "Digital measurement of the efficiency of inverter-induction machines," IEEE Trans. Ind. Appl., Vol. 26, No. 5, pp. 872-879, Sep./Oct. 1990.

[19] R. Perret, C. Schaeffer, and E. Farjah, "Temperature evolution in power semiconductor devices: Measurement techniques and simulation," in Proc. IEE Colloq. Meas. Tech. Power Electron., pp. 10/1-10/7, 1992.

[20] L. Peretto, R. Sasdelli, and G. Serra, "Measurement of harmonic losses in transformers supplying nonsinusoidal load currents," IEEE Trans. Instrum. Meas., Vol. 49, No. 2, pp. 315-319, Apr. 2000.

[21] N. Schmidt and H. Guldner, "A simple method to determine dynamic hysteresis loops of soft magnetic materials," IEEE Trans. Magn., Vol. 32, No. 2, pp. 489-496, Mar. 1996.

[22] F. D. Tan, J. L. Vollin, and S. M. Cuk, "A practical approach for magnetic core-loss characterization," IEEE Trans. Power Electron., Vol. 10, No. 2, pp. 124-130, Mar. 1995.

[23] W. Chen, L. M. Ye, D. Y. Chen, and F. C. Lee, "Phase error compensation method for the characterization of low-power-factor inductors under high-frequency large-signal excitation," in Proc. 13th Annu. Appl. Power Electron. Conf. and Expo., Vol. 1, pp. 420-424, Feb. 1998.

[24] A. Jalilian, V. J. Gosbell, and B. S. P. Perera, "Double chamber calorimeter (DCC): A new approach to measure induction motor harmonic losses," IEEE Trans. Energy Convers., Vol. 14, No. 3, pp. 680-685, Sep. 1999.

[25] C. Xiao, G. Chen, and W. G. H. Odendaal, "Overview of power loss measurement techniques in power electronics systems," IEEE Trans. Ind. Appl., Vol. 43, No. 3, pp 657-664, Jul. 2007.

[26] J. Muhlethaler, J. Biela, and J. Kolar, "Core loss under DC bias condition based on Steinmetz parameters," Proc. of ECCE-Asia 2010, pp.2430-2437, 2010.

[27] Y. Zhang, M. C. Cheng, and P. Pillay, "A Novel Hysteresis Core Loss Model for Magnetic Laminations," IEEE Tran Energy Convers., Vol. 26, No. 4, pp. 993-999, Dec. 2011.

[28] C. P. Steinmetz, "On the law of hysteresis (originally published in 1892)," Proc. IEEE, Vol. 72, No. 2, pp. 196-221, Feb. 1984.

[29] M. S. Lancarotte and A. Penteado, "Estimation of core losses under sinusoidal or non-sinusoidal induction by analysis of magnetization rate," IEEE Trans. Energy Convers., Vol. 16, No. 2, pp. 174-179, Jun. 2001.

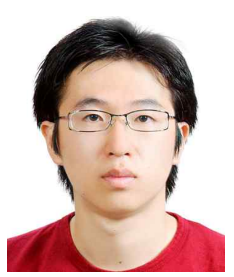

Kyoung-Jun Lee received B.S. and M.S. degrees in electrical engineering from Pusan National University, Busan, Korea in 2008 and 2010, respectively. Currently, he is working towards his Ph.D. at the School of Electrical Engineering, Pusan National University. His main research interests include power conversion of renewable energy systems, power quality and ac filter design.

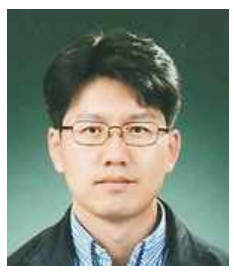

Honnyong Cha received the B.S. and M.S. degrees in electronics engineering from Kyungpook National University, Daegu, Korea, in 1999 and 2001, respectively, and the $\mathrm{Ph} . \mathrm{D}$. degree in electrical engineering from Michigan State University, East Lansing, Michigan, in 2009. From 2001 to 2003, he was a Research Engineer with Power System Technology (PSTEK) Company, An-san, Korea. From 2010 to 2011, he worked as a Senior Researcher at the Korea Electrotechnology Research Institute (KERI), Changwon, Korea. In 2011, he joined Kyungpook National University, Daegu, Korea, as an Assistant Professor in the School of Energy Engineering. His main research interests include high power dc-dc converters, dc-ac inverters, Z-source inverters, and power conversion for electric vehicle and wind power generation.

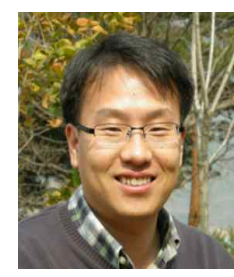

Jong-Pil Lee received a B.S. and a M.S. in Control and Instrumentation of Engineering and Electrical Engineering from Korea University, Korea in 1997 and 1999, respectively. He received his Ph.D. from Korea University, Korea, in 2012. From 1999 to 2005 , he was a senior researcher in the Electric and Hybrid Vehicle Research department of Hyundai Heavy Industries. He has been working as a senior researcher in the Power Conversion and System for Renewable Energy Center of the Korea Electro-technology Research Institute (KERI), Korea. His main research interests are photovoltaic PCS, ZVS DC/DC converters and power conversion for hybrid electrical vehicles.

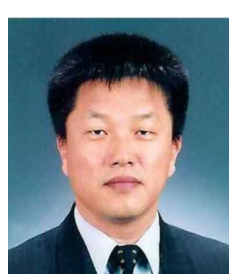

Dong-Wook Yoo received the B.S. degree in electrical engineering from Sung-Kyun-Kwan University (SKKU), Suwon, Korea, in 1983, the M.S. degree in electrical engineering from Yon-Sei University, Seoul, Korea, in 1985, and the $\mathrm{Ph}$. D. degree, majoring in power electronics, from SKKU in 1997. He became a Researcher in 1985, Senior Researcher in 1989, Principal researcher in 1997 at Korea Electrotechnology Research Institute (KERI), Changwon, Korea. Since 1997, he was a Team Leader of Power Electronics Laboratory, and Renewable Energy Laboratory at KERI.

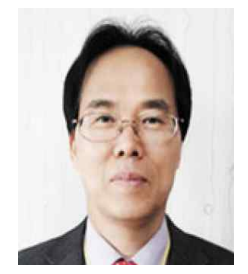

Hee-Je Kim received his B.S. and M.S. in Electrical Engineering from Pusan National University, Korea in 1980 and 1982, respectively. He received his $\mathrm{Ph} . \mathrm{D}$. from Kyushu University, Fukuoka, Japan in 1990. $\mathrm{He}$ joined the Korea Electro-technology Research Institute in 1983, and went to Kyushu University for the study of laser systems and plasma applications. From 1995 to the present, he has been a Professor in the School of Electrical Engineering, Pusan National University. 